\title{
Editorial
}

\section{eCAM: Neuroendocrineimmune, Electroacupuncture and Gene Expression}

\section{Edwin L. Cooper}

Laboratory of Comparative Neuroimmunology, Department of Neurobiology, David Geffen School Of Medicine at UCLA University of California, Los Angeles, CA 90095-1763, USA

Corresponding author: Edwin L. Cooper, Department of Neurobiology, David Geffen School of Medicine at UCLA University of California, Los Angeles, CA 90095-1763, USA. Tel: +1 (310) 825-9567; Fax: +1 (310) 825-2224; E-mail: ecam@mednet.ucla.edu

As mentioned in the first issue of volume 7, there was a review of covers and how these images could have served to prick the imagination of readers and invite esthetic appreciation of complementary and alternative medicine (CAM) before opening the pages to the scientific evidence-based work; however, covers were intended to stimulate an interest in contemporary art and how it might be related remotely to art $(1,2)$. Essentially, all of the images might be considered as high art as related to high culture and much too complicated and perhaps even inappropriate here. Suffice it to say, the works would evoke immediately for initiated the usual forms of what everyone considers art is all about. However, to depart from these and the periods in CAM early I decided to place on the covers figures that at first glance might re-sample contemporary art. There are brilliant colors, especially greens and reds, some suggestion of order often in the midst of disorder. Now, we come to the second issue and start with the origin of a portion of the title neuroendocrineimmune and its first usage in relation to $e C A M$. Next, we will treat briefly a proteomic approach to electroacupuncture (EA), departing from classical guesses and providing sound molecular interpretations. Results are all embracing: the nervous, endocrine and immune systems.

First, here is a very brief description of the covers for eCAM supplements (3, 4). Supplement 4: ETM 2007 European Traditional Medicine International Congress, Vinci, Italy, October 4-6, 2007. 'Star of Bethlehem: (Family Liliaceae, Ornithogalum umbellatum L)', Leonardo da Vinci, Italy; pen and ink over chalk on paper. Reproduced by the kind permission of the Royal
Collection 2006 Her Majesty Queen Elizabeth II. The concept of nature is fundamental in Leonardo's art. The Star of Bethlehem is an ornamental plant; the florescence can bear 20 flowers. It is a toxic plant and poisonous if ingested, it contains cardiac glycosides in all parts with the bulbs containing a higher percentage of the toxin. Preliminary studies in the 1970s were devoted to its possible treatment of heart failure but these were abandoned. Supplement 6: Sasang Constitutional Medicine: as a Holistic Tailored Medicine. The Banquet of Seowangmo (Xiwangmu), Queen Mother of the West. Joseon Dynasty (1392-1910), 18-19th Century Screen/ Scroll, painting. Eight-panel screen, ink, color and gold on silk.

\section{Can eCAM be Scientific? Lessons from Immunology}

According to Burnet (5):

The first objective in a serious approach to immunology should be to obtain a broad understanding, with a minimum of detail, of how immunology fits into the pattern of biology — of the way in which the immune system evolved, its function and coordination with other body systems, and its development from the embryo onwards. At the same time, such an outline should provide an adequate background for easy application of immunological ideas to the detail of practical immunological work in public health, clinical, and veterinary practice. 
After reading this, I paraphrased it immediately to fit the context of $e C A M$ so that it reads: 'the first objective in a serious approach to CAM should be to obtain a broad understanding, with a minimum of detail, of how CAM fits into the pattern of biology - of the way in which the neuroendocrineimmune system evolved, its function and coordination with other body systems, and its development from the embryo onwards. At the same time, such an outline should provide an adequate background for easy application of CAM ideas to the detail of practical CAM work in public health, clinical and medical practice, and yet not stray far away from the very biology that under girds it. CAM is organismic, inclusive and not reductionist and exclusive (6-9).

Turning now to the current example of CAM and its fit with molecular approaches, toward a greater understanding of mechanisms that are evidence based. For the uninitiated, EA is defined according to Acupuncture Today, 'Electroacupuncture is quite similar to traditional acupuncture in that the same points are stimulated during treatment. As with traditional acupuncture, needles are inserted on specific points along the body. The needles are then attached to a device that generates continuous electric pulses using small clips. These devices are used to adjust the frequency and intensity of the impulse being delivered, depending on the condition being treated. Electroacupuncture uses two needles at time so that the impulses can pass from one needle to the other. Several pairs of needles can be stimulated simultaneously, usually for no more than 30 minutes at a time.'

Moreover, that article adds: 'According to the principles of traditional Chinese medicine, illness is caused when chi does not flow properly throughout the body. Acupuncturists determine whether chi is weak, stagnant or otherwise out of balance, which indicates the points to be stimulated. Electroacupuncture is considered to be especially useful for conditions in which there is an accumulation of chi, such as in chronic pain syndromes, or in cases where the chi is difficult to stimulate.' EA is also variously termed EA, electro-acupuncture or incorporated under the generic term electrotherapy.

\section{Clustering Analysis and Gene Ontology Analysis}

A CAM research team in Korea has provided exemplary research (10). 'Clinical evidence indicates that EA is effective for allergic disorder. Animal models revealed that EA treatment reduces levels of $\operatorname{IgE}$ and $\mathrm{Th} 2$ cytokines in $\mathrm{BALB} / \mathrm{c}$ mice immunized with 2,4-dinitrophenylated keyhole limpet protein (DNP-KLH). The hypothalamus, a brain center of the neuroimmune system, is activated by EA stimulation. One crucial goal was to identify and characterize differentially expressed genes in the hypothalamus of DNP-KLH immunized mice that had been stimulated with EA. As evidence, they conducted a microarray analysis to evaluate the global gene expression profiles, using the hypothalamic RNA samples taken from three groups of mice: (i) $\mathrm{NC}$ group (no treatments); (ii) IMH group (DNP-KLH immunization + restraint); and (iii) IMEA group (immunization + EA stimulation).

The microarray analysis revealed that a total of 39 genes were altered in their expression levels by EA treatment. Ten genes, including T-cell receptor alpha variable region family 13 subfamily 1 (Tcra-V13.1), heat-shock protein 1B (Hspalb) and 2'-5' oligoadenylate synthetase $1 \mathrm{~F}$ (Oas1f), were up-regulated in the IMEA group when compared to the IMH group. In contrast, 29 genes, including decay accelerating factor 2 (Daf2), NAD (P) $\mathrm{H}$ dehydrogenase, quinone 1 (Nqo1) and programmed cell death 1 ligand 2 (Pdcd1lg2) were down-regulated in the IMEA group as compared to the IMH group'.

Results are significant and constitute a milestone in elevating CAM effects beyond the ancient approaches. Their results reveal that EA treatment can modulate immune responses in DNP-KLH immunized mice by regulating expression levels of genes that are associated with innate immune, cellular immunity and/or other kinds of immune system associated with influences of the hypothalamus. These kinds of results provide strong evidence for linkages between the three regulatory systems: nervous, endocrine and immune. This is the kind of approach that we are striving for-CAM procedures that produce solid non-conjectural evidence-thus pushing back the fog that has often obscured the significance of $\mathrm{CAM}$ and integrative medicine practices.

\section{References}

1. Cooper EL. eCAM: Proteomics, BioArt and Integrative Medicine? eCAM 2010;7:1-2.

2. Matsumoto C, Kojima T, Ogawa K, Kamegai S, Oyama, T, Shibagaki $\mathrm{Y}$, et al. A proteomic approach for the diagnosis of 'Oketsu' (blood stasis), a pathophysiologic concept of Japanese traditional (Kampo) medicine by a group in Japan. eCAM 2008; 5:463-74.

3. ETM 2007 EUROPEAN TRADITIONAL MEDICINE International Congress VINCI, ITALY -October 4-6, 2007 Evidence-based Complementary and Alternative Medicine 2007 Sep; 4 (Suppl 1) $<\mathrm{http}$ ://ecam.oxfordjournals.org/content/vol4/suppl_1/>: 1-70.

4. Sasang Constitutional Medicine Supplement Evidence-based Complementary and Alternative Medicine 2009 Sep; 6 (Suppl 1) $<$ http://ecam.oxfordjournals.org/content/vol6/suppl_1/>: 1-103.

5. Burnet FM. Immunology, Aging and Cancer. San Francisco: W.H. Freeman and Company, 1976, 62.

6. Cooper EL. Complementary and alternative medicine, when rigorous, can be science. eCAM 2004;1:1-4.

7. Cooper EL (ed.). Stress, Immunity and Aging. New York: NY Marcel Dekker Inc, 1984.

8. Cooper EL. Cooper EL (ed.). Stress, Immunity and Aging. New York: NY Marcel Dekker, Inc, 1984, 13-26.

9. Cooper EL, Brazier MAB (eds). Developmental Immunology: Clinical Problems and Aging. UCLA Forum in Medical Sciences, Vol. 25. New York: NY Academic Press, 1982.

10. Kim SK, Kim J, Ko E, Kim H, Hwang SD, Lee S, et al. Gene expression profile of the hypothalamus in DNP-KLH immunized mice following electroacupuncture stimulation; doi:10.1093/ecam/ nep222 [E-pub ahead of print February 11, 2010]. 


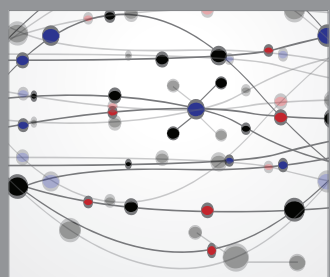

The Scientific World Journal
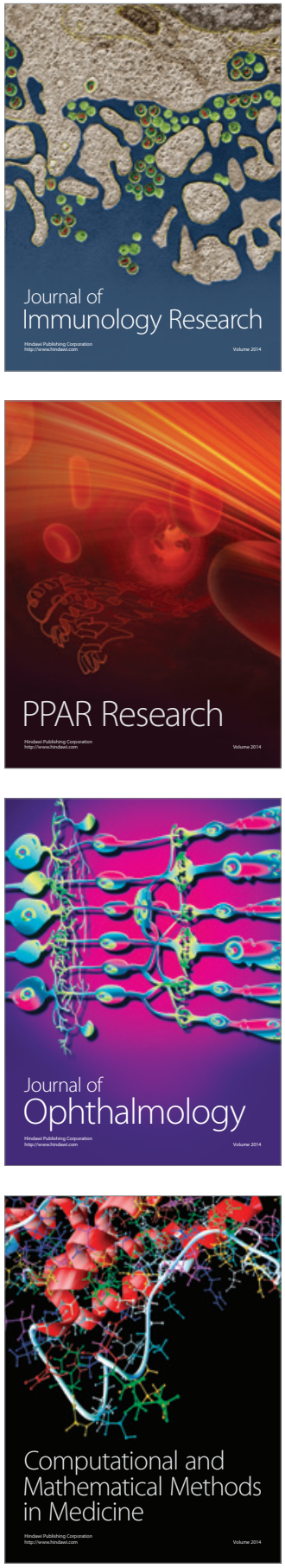

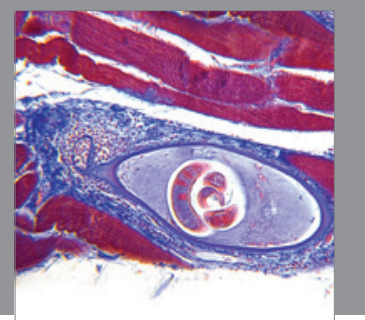

Gastroenterology

Research and Practice
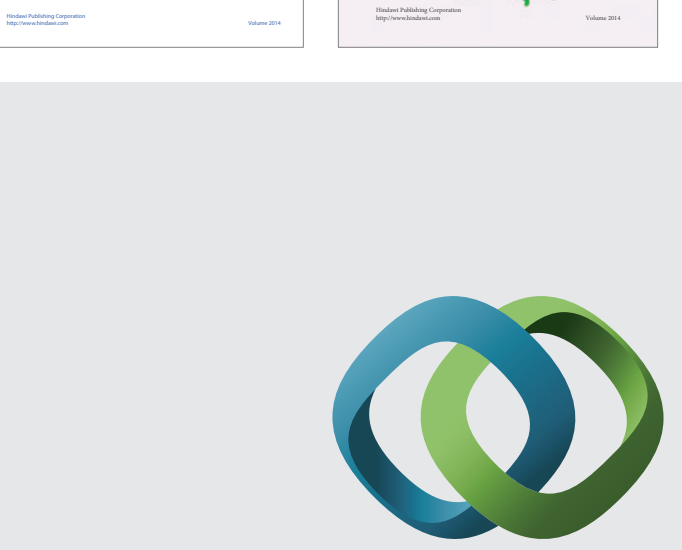

\section{Hindawi}

Submit your manuscripts at

http://www.hindawi.com
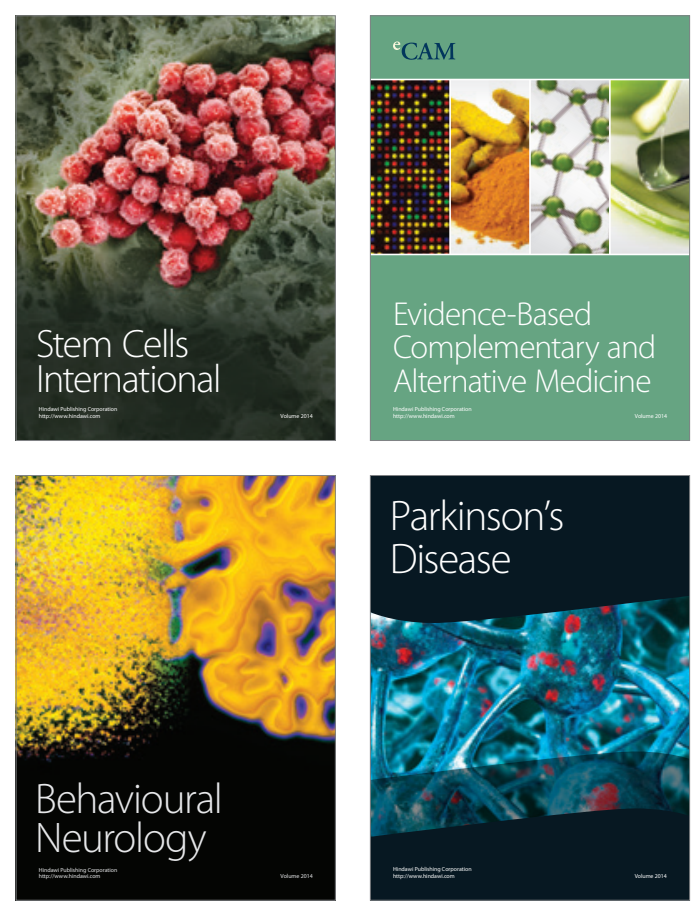

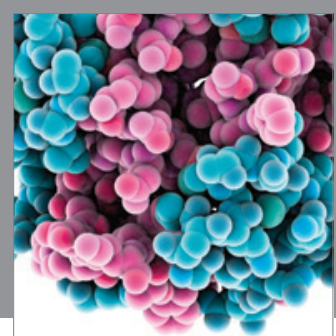

Journal of
Diabetes Research

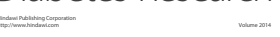

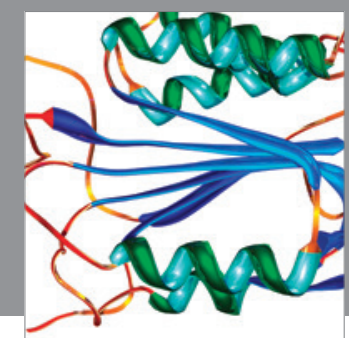

Disease Markers
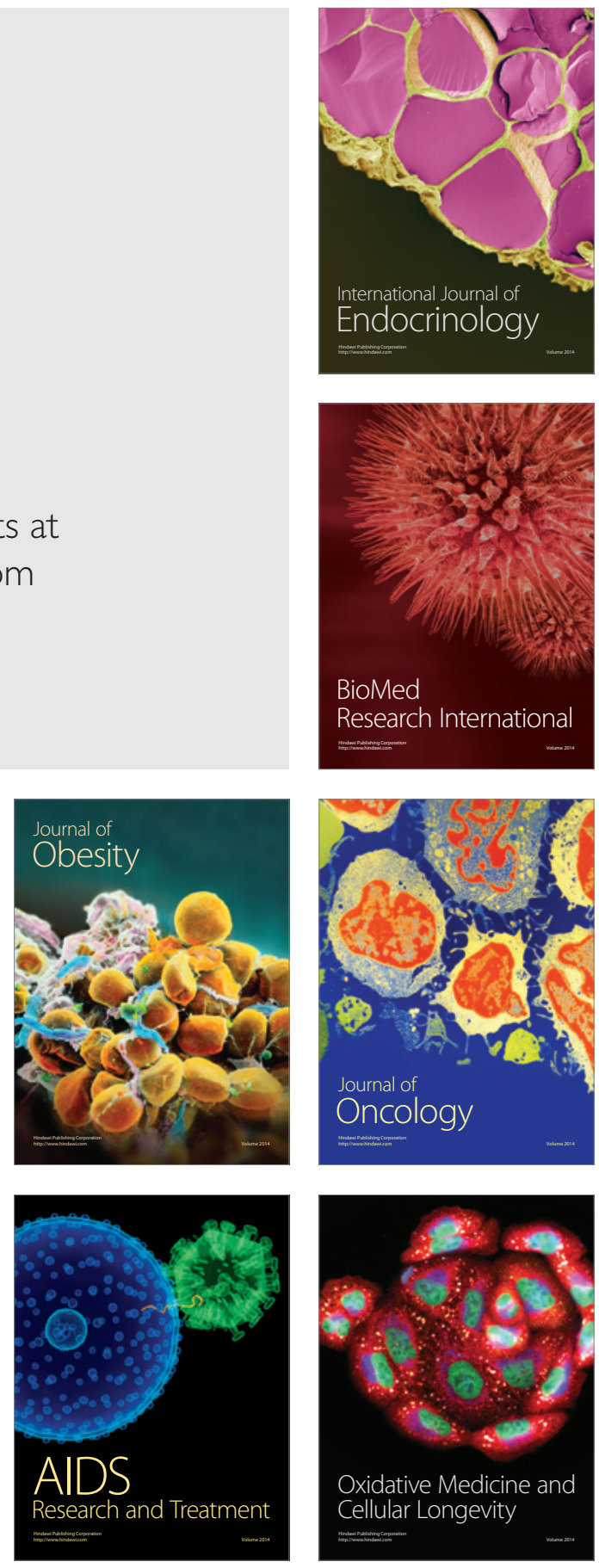